\title{
AN EXHAUST MANIFOLD PRESSURE ESTIMATOR FOR A TWO-STAGE TURBOCHARGED DIESEL ENGINE
}

\author{
Fabio Chiara, Marcello Canova \\ Center for Automotive Research \\ The Ohio State University \\ Columbus $\mathrm{OH} 43212$ \\ chiara.2@osu.edu
}

\author{
Yue-Yun Wang \\ General Motors Research, \\ Development and Strategic Planning \\ Warren, MI 48090 \\ yue-yun.wang@gm.com
}

\begin{abstract}
The exhaust manifold pressure is a crucial variable for turbocharged Diesel engines, affecting the torque production and the emissions through variations in the EGR mass flow and in the residual mass fraction in the cylinder. This variable is therefore considered very relevant for closed-loop EGR and turbocharger control.

However, in production applications, the cost of the pressure sensor and the particularly harsh environment where this must work are practical barriers to its actual implementation. Therefore, the need for a rapid, reliable and robust estimation of this variable from low-cost production sensors is strong, above all, in the contest of advanced engine powertrains.

This work describes the development of an estimator for the exhaust manifold pressure in a turbocharged Diesel engine with two-stage turbocharger. The approach proposed relies on a feed-forward scheme based on the inversion of a two-stage turbocharger model, which includes the radial turbines, nozzles and valves. Calibration and validation results of the estimator are presented in both steady-state and transient operating conditions.
\end{abstract}

\section{INTRODUCTION}

The more and more stringent emissions regulations for Diesel engines have forced engine designers to considerably refine the existing control strategies to further reduce engine-out emissions. In particular, it is well understood that the use of Exhaust Gas Recirculation (EGR), coupled with dedicated aftertreatment system, has become the solution of choice for the reduction of $\mathrm{NO}_{\mathrm{x}}$ on Diesel engines. Considerable research work has been done in the past to determine control schemes to manage the fraction of combustion products that is re-induced to the intake [1-5]. The traditional control strategies adopted in modern turbocharged Diesel engines is based on coupled
EGR-VGT control schemes, attempting at regulating the boost pressure and the EGR fraction based on measurements of intake manifold pressure and air mass flow rate $[4,5]$.

It is well known that the EGR mass flow strictly depends upon the differential pressure between the exhaust and the intake manifold. However, measuring the exhaust manifold pressure is rather complex, due to the costs and complexity related to the installation of a pressure sensor in the exhaust manifold or an additional differential pressure sensor across the EGR valve. For this reason, the traditional approach to engine control attempt at overcoming the sensor limitations by calibration and experimental tests, implementing the information in openloop (feed-forward) correction tables. This impacts the performance and the accuracy of the controllers, limiting the benefits on NOx emissions reduction and on the engine efficiency (which is directly affected by the differential pressure between the exhaust and the intake manifold).

To overcome the limitations of the traditional, calibrationbased methods, a model-based approach could be adopted to provide an estimation of the exhaust manifold pressure, based on limited sensors information. In light of reducing costs and complexity of modern Diesel engines, several estimation methods have been developed. In [6], a system for estimating engine exhaust pressure is presented with reference to a turbocharged Diesel engine. Similarly, an approach for estimating the exhaust manifold pressure by means of characterizing the engine exhaust system as a restriction is presented in [7]. In [8], an algorithm for estimating the exhaust manifold pressure is presented for the case of a Diesel engine with variable geometry turbocharger.

This work presents a novel approach to the estimation of the exhaust manifold pressure in a Diesel engine with two-stage turbocharger. The estimator accounts for the various operating modes of the turbocharger, namely the 
effects of the high-pressure turbine VGT and bypass, and the low-pressure waste-gate valve.

The approach is first illustrated for a simplified case of single stage turbine and then applied to the more complex case of a two turbines in series configuration. Validation results against a $1 \mathrm{D}$ thermo-fluid engine system simulation model (GT-Power) are shown.

\section{DESCRIPTION OF THE EXHAUST PRESSURE ESTIMATOR}

The estimation scheme for the exhaust manifold pressure of a turbocharged engine is based on the inversion of a grey box, quasi-static model that is generally adopted to characterize the flow in a radial turbine [9, 10]. This type of model is practical for this purpose as it does not need the knowledge of the turbocharger speed to predict the pressure ratio across the turbine, provided the mass flow of the exhaust gases is known. The turbine flow is generally specified in terms of corrected mass flow rate, which is related to the (dimensional) mass flow rate as:

$$
\dot{m}_{\text {corr }}=\dot{m}_{T B}\left(\frac{\sqrt{T_{i n}}}{p_{\text {in }}}\right)
$$

where $p_{\text {in }}$ and $T_{\text {in }}$ are the inlet conditions, and the reference parameters $p_{r e f}$ and $T_{r e f}$ are provided by the turbocharger manufacturer. An example of a turbine flow map for fixedgeometry turbine is shown Fig. 1.

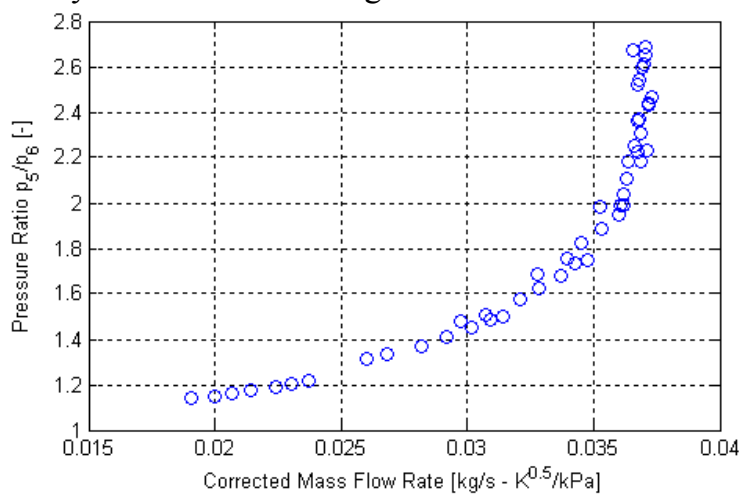

FIGURE 1. PRESSURE RATIO (Y-AXIS) VS CORRECTED FLOW RATE FOR FIXED-GEOMETRY TURBINE

The flow model of radial turbine generally assumes the device as a quasi-steady nozzle, hence applying the equations for compressible flow. Best accuracy with the experimental flow maps (such as shown in Figure 1) is obtained with the model [11]:

$$
\begin{gathered}
\dot{m}_{c o r r}=\Omega_{e q} \frac{p_{r e f}}{\sqrt{R T_{r e f}}} f_{1}(\varepsilon) \\
\sqrt{\frac{2 \gamma}{\gamma-1}\left[\varepsilon^{-\frac{2}{m}}-\varepsilon^{-\frac{m+1}{m}}\right]} \quad \text { if } \quad \varepsilon<\left(\frac{2}{m+1}\right)^{\frac{m}{m-1}} \\
\left(\frac{2}{m+1}\right)^{\frac{1}{m-1} \sqrt{\frac{2 \gamma}{\gamma-1} \frac{m-1}{m+1}}} \quad \text { otherwise }
\end{gathered}
$$

where $\varepsilon=p_{\text {in }} / p_{\text {out }}$ is the pressure ratio across the turbine and $\gamma$ is the specific heat ratio for air treated as ideal gas. The parameters of Equations 2 and 3, namely the turbine equivalent area $\Omega_{e q}$ and the coefficient $m$ (constant for a fixed geometry turbine) can be identified from the turbine flow map. The parameter $m$ accounts for the non-isentropic behavior of a real turbine, as well as for the composition of the exhaust gases. Finally, the dimensional mass flow rate can be predicted by Inverting Equation 1.

The turbine model above can be applied to estimate the inlet pressure $p_{i n}$, for known thermodynamic conditions downstream the turbine $\left(p_{\text {out }}, T_{\text {out }}\right)$ and mass flow rate. Manipulating Equation 1 yields:

$$
\dot{m}_{T B}=\dot{m}_{\text {corr }} \frac{p_{\text {out }}}{\sqrt{T_{\text {out }}}} \varepsilon^{\frac{1+m}{2 m}}
$$

where the parameter $m$ can be estimated from the efficiency maps of the turbine [10]. The efficiency can be related to the exponent $m$ by the expression:

$$
m=\frac{\ln (\varepsilon)}{\ln (\varepsilon)+\ln \left[1-\eta_{L P}(\varepsilon)\left(1-\varepsilon^{\frac{1-\gamma}{\gamma}}\right)\right]}
$$

Combining Equation 4 with Equation 2 yields:

$$
\dot{m}_{T B}=\Omega_{\text {eq }} \frac{p_{\text {ref }}}{\sqrt{R T_{\text {ref }}}} \frac{p_{\text {out }}}{\sqrt{T_{\text {out }}}} \varepsilon^{\frac{1+m}{2 m}} f_{1}(\varepsilon)
$$

The above expression can be used to scale the dimensional mass flow rate into a corrected mass flow rate, with respect to the thermodynamic conditions downstream the turbine:

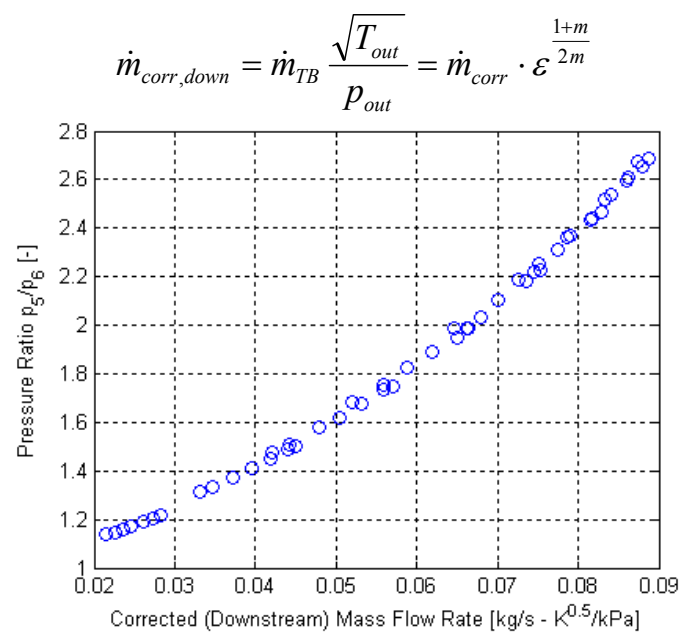

\section{FIGURE 2. CONVERTED TURBINE FLOW MAP, BASED} ON DOWNSTREAM CONDITIONS (DATA FROM FIG. 1).

The results of the transformation described above are illustrated in Fig. 2, which shows the converted turbine flow map based on the downstream thermodynamic conditions. The curve obtained lends itself to be approximated with a power function:

$$
\dot{m}_{\text {corr }, \text { down }}=\dot{m}_{T B} \frac{\sqrt{T_{\text {out }}}}{p_{\text {out }}} \cong a_{0} \cdot\left(\varepsilon^{a_{1}}+a_{2}\right)
$$


where the parameters $a_{0}, a_{1}, a_{2}$ can be identified on engine data or using the modified turbine map shown in Fig. 2. This can be also demonstrated mathematically, by combining Equation 7 with Equation 3.

Since it is generally $\varepsilon \geq 1$, the formula above can be inverted to express the pressure ratio and, ultimately, the upstream pressure as the output:

$$
p_{\text {in }}=\left(\frac{\dot{m}_{\text {corr }, \text { down }}-a_{0} a_{2}}{a_{0}}\right)^{\frac{1}{a_{1}}} \cdot p_{\text {out }}
$$

Equation (9) may be used as a feed-forward estimator of the exhaust manifold pressure for a single-stage, fixed geometry turbine, starting from the outputs of production sensors. In fact, the pressure and temperature downstream of the turbocharger are measured for aftertreatment control and diagnostics. The exhaust flow can be estimated quite accurately as the sum of the air mass flow (measured) and the fuel flow.

Note that the estimator is based on quasi-static approach, leading to a purely algebraic equation. As will be shown in the following sections, this assumption is reasonable for automotive turbochargers, where the small volume of the components leads to negligible mass and energy storage dynamics for the frequencies of interest (typically in the range of $10^{-1}-10^{1} \mathrm{~Hz}$ ). An additional feedback loop could be included to improve the accuracy of the estimator.

\section{EXHAUST PRESSURE ESTIMATION FOR A DIESEL ENGINE WITH TWO-STAGE TURBOCHARGER}

The approach to exhaust manifold pressure estimation above presented is here applied to a two stage turbocharger in series configuration. The turbocharger system, shown in Fig. 3, is characterized by a variable geometry HP turbine with bypass valve and a fixed geometry LP turbine with waste-gate valve [13].

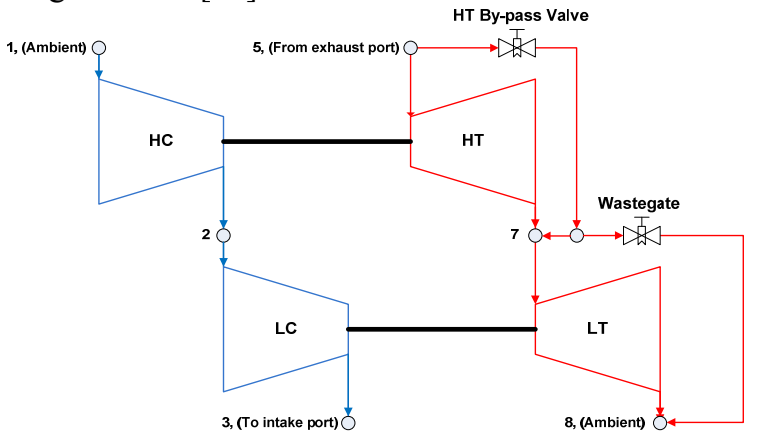

FIGURE 3. PLANT DIAGRAM OF THE TWO STAGE TURBOCHARGER SYSTEM DESCRIBED IN [13].

The exhaust pressure estimator is obtained by inverting the models of the two turbines, assuming that the only available measurements are the pressure and the temperature downstream the LP turbine and the inlet air mass flow rate (MAF). Such assumption is consistent with the typical sensor arrangement for production Diesel engines, as outlined above. With reference to the notation in Fig. 3, the required inputs are the LP turbine-out pressure and temperature ( $p_{8}$ and $T_{8}$ respectively), and the exhaust gas mass flow rate $\left(\dot{m}_{\text {exh }}\right)$.

In addition, the positions of the waste-gate (WG), VGT and HP turbine bypass actuators are given as additional inputs to the estimator. Fig. 4 and Fig. 5 show a block diagram of the estimator and a more detailed representation of the HP and LP modules.

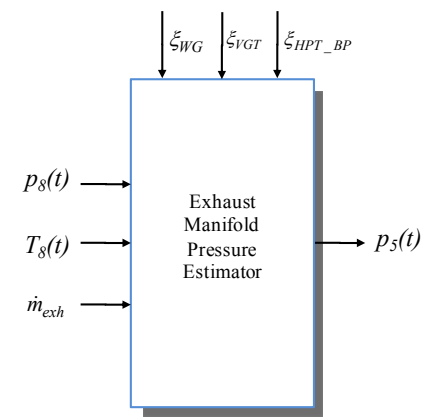

FIGURE 4. BLOCK DIAGRAM OF THE PRESSURE

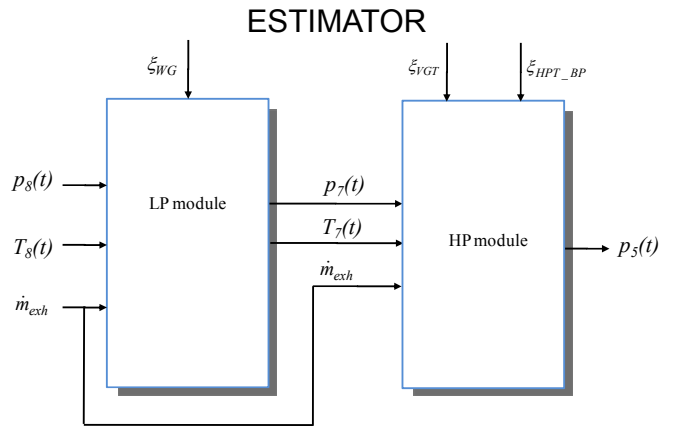

FIGURE 5. STRUCTURE OF THE EXHAUST MANIFOLD PRESSURE ESTIMATOR

For a two-stage turbocharger in series configuration, the estimation of the exhaust manifold pressure $p_{5}$ can be obtained by applying Equation 9 to the LP module and to the HP module. In doing so, a challenging issue is the determination of the thermodynamic conditions (specifically, the temperature) between the two modules, which has a considerable influence on the accuracy of the results.

In order to design the pressure estimator for the the LP module, the LP turbine and the WG valve are assumed as two nozzles operating in parallel configuration. Similarly the HP module is based on modeling the HP turbine and HP bypass valve parallel configuration as an equivalent nozzle. It is important to observe that the assumption above constitutes an approximation of the real behavior of the system. Automotive turbochargers are typically characterized by unsteady pulsating flow, which causes strong interactions between the turbine and the valve in parallel [12]. This approximation may lead to inaccuracies for high speed and load conditions, where the bypass or the waste-gate is open. However, for the engine operating range relevant for the FTP cycle, the assumption introduced does not lead to loss of accuracy. 
As stated above, the LP turbine-out pressure and temperature ( $p_{8}$ and $T_{8}$ respectively) must be measured to utilize the estimator. The exhaust mass flow rate is reasonably approximated as the sum of the engine air mass flow rate (measured) and the fuel mass flow rate (estimated from fuel injection calibration maps).

Description of the LP module. The low pressure module is characterized by the inversion of the model of the parallel between the LP turbine and the WG valve. The corrected mass flow rate through the LP turbine is modeled using Equations 2-3 above, where $\varepsilon=p_{7} / p_{8}$ is the pressure ratio across. The model parameters, namely the equivalent area $\Omega_{e q}$ and the exponent coefficient $m$, can be determined from the turbocharger maps.

Similarly, the corrected mass flow rate of exhaust gas through the WG can be approximated by using the model of an isentropic nozzle:

$$
\begin{gathered}
\dot{m}_{\text {corr }_{-} W G}=C_{d} A\left(\xi_{W G}\right) \frac{p_{\text {ref }}}{\sqrt{R T_{\text {ref }}}} f_{2}(\varepsilon) \\
f_{2}(\varepsilon)=\left\{\begin{array}{l}
\sqrt{\frac{2 \gamma}{\gamma-1}\left[(\varepsilon)^{-\frac{2}{\gamma}}-(\varepsilon)^{-\frac{(\gamma+1)}{\gamma}}\right]} \quad \text { if } \quad \varepsilon<\varepsilon_{\text {crit }} \\
\sqrt{\left(\frac{2}{\gamma+1}\right)^{\frac{\gamma+1}{\gamma-1}}} \quad \text { if } \quad \varepsilon>\varepsilon_{\text {crit }}
\end{array}\right.
\end{gathered}
$$

where $C_{d} A\left(\xi_{W G}\right)$ is the effective area of the valve, $\gamma=c_{p} / c_{v}$ is the specific heat ratio. Under quasi-steady conditions, the total corrected mass flow rate through the LP turbine and the WG is the sum of the individual flows:

$$
\dot{m}_{\text {corr } L P P_{-} \text {tot }}=\dot{m}_{\text {corr_ }_{-} L P}+\dot{m}_{\text {corr }-W G}=\Phi\left(\varepsilon, \xi_{W G}\right)
$$

By comparing Equation 2 with Equation 11, the function $\Phi\left(\varepsilon, \xi_{W G}\right)$ can be expressed as:

$$
\dot{m}_{{\text {corr_ } L P P_{-} t o t}}=\Omega\left(\xi_{W G}\right) \frac{p_{\text {ref }}}{\sqrt{R T_{\text {ref }}}} f_{3}\left(\varepsilon, \xi_{W G}\right)
$$

where the function $f_{3}\left(\varepsilon, \xi_{W G}\right)$ has the same expression of $f_{2}(\varepsilon)$, but the parameter $m$ becomes now a function of the WG opening.

The model of the parallel between the LP turbine and the WG was identified using the LP turbine map data and the parameters of the WG valve model.

$$
\dot{m}_{L P_{-} t o t}=\dot{m}_{\text {corr_- } L P_{-} \text {tot }} \cdot \frac{p_{7}}{\sqrt{T_{7}}}
$$

Once the equivalent model of the LP-turbine and WG assembly is built, it is possible to apply the model-based estimator to determine the upstream pressure $p_{7}$, namely the intermediate pressure between HP and LP stage (Equations 7-8):

$$
\frac{p_{7}}{p_{8}}=a\left(\xi_{W G}\right) \cdot\left(\dot{m}_{L P_{-} t o t} \cdot \frac{\sqrt{T_{8}}}{p_{8}}\right)^{b\left(\xi_{W G}\right)}+c\left(\xi_{W G}\right)
$$

The parameters $a, b$ and $c$ are functions of the wastegate opening $\xi_{W G}$, and can be identified using simulation data or experimental results on a test engine.

Description of the HP module. The HP module of the exhaust manifold pressure estimator is derived from the same approach used for the LP module. The first step is the definition of an equivalent model of the parallel between the HP turbine and the bypass valve. The equations and the related parameters are the same implemented in the previous version.

Once the equivalent model is built and identified, the actual mass flow rate through the HP module can be calculated in the following way:

$$
\dot{m}_{H P_{-} t o t}=\dot{m}_{\text {corr }-H P_{-}+t o t} \cdot \frac{p_{5}}{\sqrt{T_{5}}}
$$

where $p_{5}$ and $T_{5}$ are the exhaust manifold pressure and temperature respectively.

The estimator can be obtained by applying the same procedure described for the LP module. However, the downstream temperature is now known in this case, as it depends on the behavior of the LP turbine. Therefore, a different procedure must be applied, consisting in separately estimating the temperature upstream the LP module. A simple approach could be based on the thermodynamics of a radial turbine stage, where a polytropic transformation is defined [12]:

$$
T_{7}=T_{8} \cdot\left(\frac{p_{7}}{p_{8}}\right)^{\frac{\delta-1}{\delta}}
$$

where the polytropic coefficient $\delta$ can be calibrated based on the LP turbine efficiency map. Dividing both sides by $p_{7}$ and considering that $T_{5}$ can be expressed as a function of $T_{7}$ and $\varepsilon$ through another polytropic expansion, the following equation for $\dot{m}_{H P_{-} t o t}$ can be derived:

$$
\dot{m}_{H P_{-} t o t} \cdot \frac{\sqrt{T_{7}}}{p_{7}}=\dot{m}_{\text {corr }_{-} H P_{-} t o t} \cdot \varepsilon^{\frac{1}{\mu}}=\bar{\Phi}\left(\varepsilon, \xi_{H P T_{-} B P}, \xi_{V G T}\right)
$$

If the parameter $\mu$ were estimated from the HP turbine efficiency map, a value in the range of 1.2-1.5 would be obtained, in relation with on the VGT and BP openings. The function $\bar{\Phi}$ is monotonic and can be inverted:

$$
\varepsilon=\bar{\Phi}^{-1}\left(\dot{m}_{H P_{-} t o t} \cdot \frac{\sqrt{T_{7}}}{p_{7}}, \xi_{H P T_{-} B P}, \xi_{V G T}\right)
$$

Similarly to the previous cases, the function $\bar{\Phi}^{-1}$ can be well approximated by a power law:

$$
\varepsilon=a\left(\xi_{H P T_{-} B P}, \xi_{V G T}\right) \cdot\left(\dot{m}_{H P_{-} t o t} \cdot \frac{\sqrt{T_{7}}}{p_{7}}\right)^{b\left(\xi_{H P T_{-} B P}, \xi_{V G T}\right)}+c\left(\xi_{H P T_{-} B P}, \xi_{V G T}\right)
$$

where the coefficients $a, b$ and $c$ are functions of the HP turbine bypass and VGT opening positions. Similar to the LP module, the HP module parameters can be identified on simulation or experimental data. 


\section{CALIBRATION AND VALIDATION OF THE EXHAUST PRESSURE ESTIMATOR}

The calibration of the LP and HP modules of the exhaust manifold pressure estimator was performed using simulation results for about 100 engine steady-state conditions covering the operating range [13]. The model was utilized as a "virtual engine", providing the data to identify the three parameters $a, b$ and $c$ of Equation 15 .

Fig. 6 and 7 show the results of the identification of the parameters $a, b$ and $c$ for the LP and HP module respectively. The figures compare the value of the pressure ratio $(\varepsilon)$ across the HP and LP turbines predicted by the model of the Diesel engine and estimated by the estimator, in relation with the exhaust mass flow rate corrected with respect to downstream conditions. The parameters of the LP and HP module of the estimator, identified through the procedure discussed above, were stored in look-up tables.

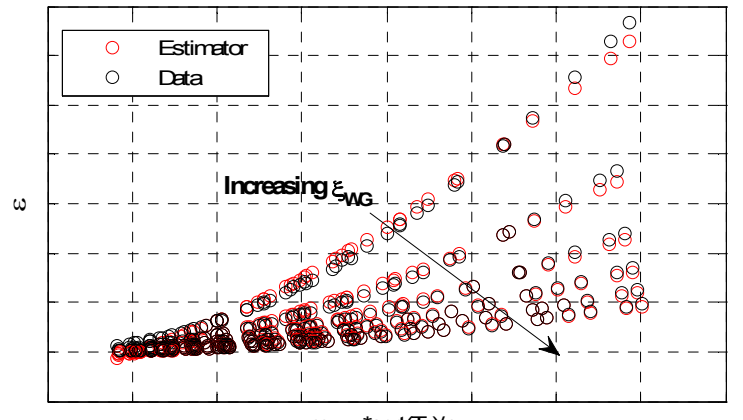

$\mathrm{m}_{\text {Rot }}{ }^{*} \operatorname{sqt}\left(\mathrm{T}_{8}\right) / \mathrm{p}_{8}$

FIGURE 6. RESULTS OF THE ESTIMATOR CALIBRATION (LP MODULE).

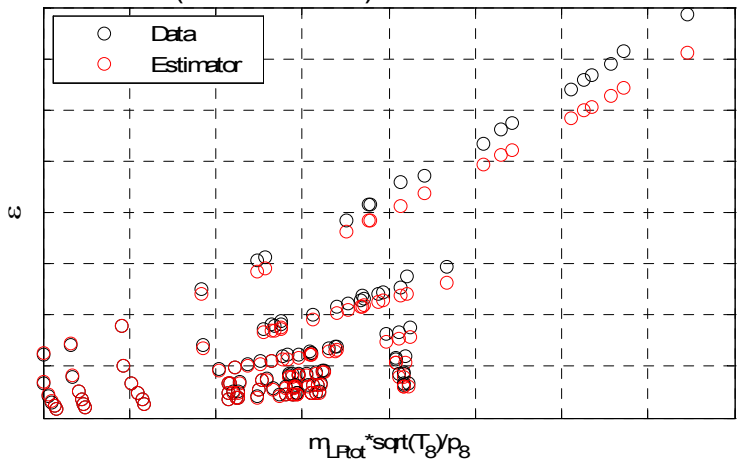

FIGURE 7. RESULTS OF THE ESTIMATOR CALIBRATION (HP MODULE).

In order to validate the pressure estimator, a set of steady state simulations was run on a high-fidelity 1D gas dynamic model for engine system simulation (GT-Power), previously calibrated on the same Diesel engine [13]. The validation process was conducted at 118 operating conditions different from those used for the calibration. The operating conditions tested were chosen so as to cover the complete engine operating map, including several combinations of waste-gate, bypass and VGT openings as well as EGR ratios.

Fig. 8 shows the results of the steady state validation of the estimator. The values of the exhaust manifold pressure predicted by the gas dynamic model and estimated by the exhaust manifold pressure estimator are presented at different steady state operating conditions (Test Number).

The estimated values of the exhaust pressure are generally very close to the values predicted by the model. A slight deviation from the actual experimental values was observed at high speed and load conditions when the bypass valve of the HP turbocharger is actuated. This is strictly related to the intrinsic limitations of the simplified pseudo-physic models used to characterize the turbocharger and the valves, which oversimplify the system behavior when complex mixing phenomena occur.

Fig. 9 shows the relative error of the exhaust manifold pressure estimation, calculated with respect to the model results:

$$
\operatorname{Error}[\%]=\frac{\hat{p}_{5}-p_{5 \_\bmod }}{p_{5 \_ \text {mod }}} \cdot 100
$$

where $\hat{p}_{5}$ and $p_{5 \bmod }$ are the estimated and model values of the exhaust manifold pressure respectively.

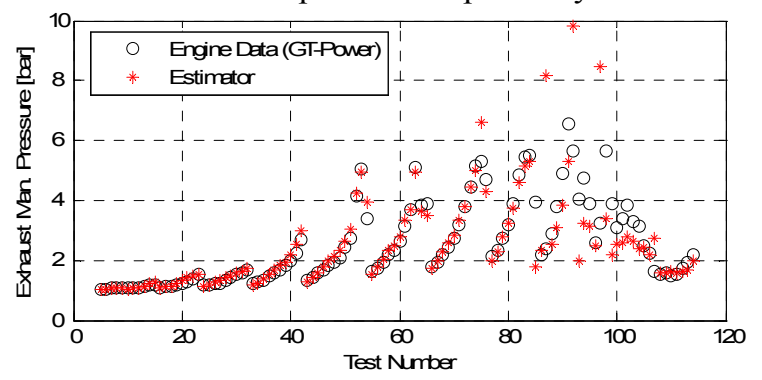

FIGURE 8. SUMMARY OF STEADY STATE VALIDATION RESULTS

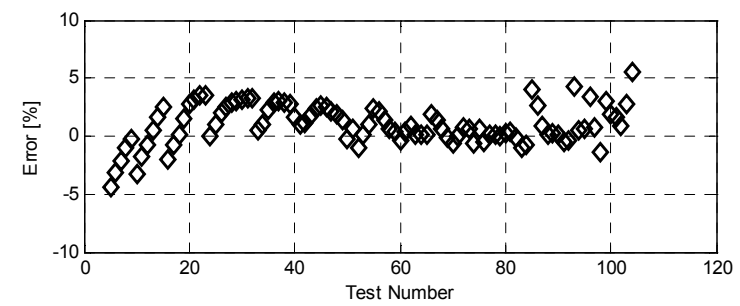

FIGURE 9. ERROR ON THE EXHAUST MANIFOLD PRESSURE ESTIMATION

The exhaust manifold pressure estimate is significantly close to the model results. In fact, as Fig. 9 shows, the exhaust manifold pressure estimation is generally affected by $\pm 4 \%$ maximum error. In a limited number of cases, a slightly larger error was observed due to the complex mixing phenomena occurring at the opening of the bypass valve of the HP turbocharger.

A sensitivity study was conducted in steady-state conditions to evaluate the robustness of the exhaust manifold pressure estimator to errors (offset and gain) affecting the available measurements. In particular, a relatively high sensitivity of the estimated pressure to the air mass flow measurement was found, whereas negligible sensitivity to the outlet LP turbine pressure and temperature was observed. 


\section{EXHAUST MANIFOLD PRESSURE ESTIMATION IN TRANSIENT CONDITIONS}

In addition to the steady-state tests, the estimator of the exhaust manifold pressure was tested on the FTP cycle, using the high-fidelity 1D gas dynamic engine simulation model as a "virtual engine". Figures 10 and 11 show the results of the validation test, where the estimated exhaust pressure is compared to the model prediction.

Similar to the steady-state validation case, the inputs to the estimator are the thermodynamic conditions downstream the LP turbine $\left(p_{8}, T_{8}\right)$ and the exhaust gas mass flow rate. This term was computed as the sum of the air mass flow rate $(M A F)$ and fuel mass flow rate, without considering any correction due to the intake manifold filling dynamics or the cylinder combustion delay.

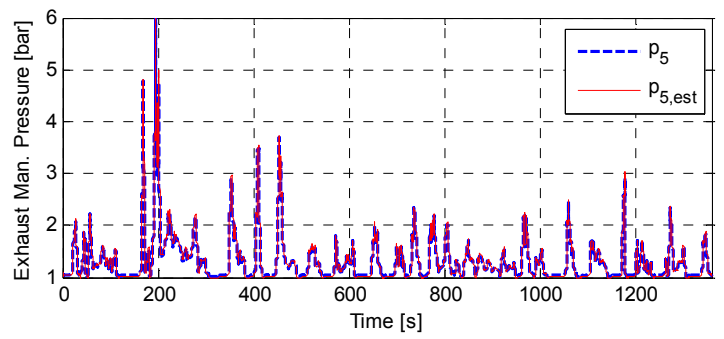

FIGURE 10. COMPARISON OF ESTIMATOR AND MODEL PREDICTIONS FOR EXHAUST MANIFOLD PRESSURE $\left(P_{5}\right)$ DURING FTP CYCLE

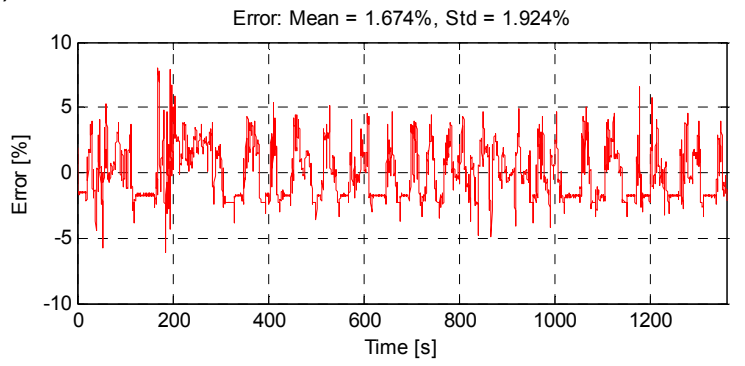

FIGURE 11. ESTIMATOR ERROR ON EXHAUST MANIFOLD PRESSURE $\left(P_{5}\right)$ DURING FTP CYCLE

The accuracy of the estimator in dynamic conditions seems quite satisfactory, leading to a mean error of approximately $1.7 \%$ with a peak of about $7 \%$. Considering that the proposed estimator is based on a feed-forward scheme and obtained by performing the inversion of a steady-state plant model, the level of accuracy obtained is sufficient for exhaust pressure and EGR estimation.

\section{CONCLUSION}

The paper presents the development of a feed-forward estimation algorithm for the exhaust manifold pressure in a turbocharged engine. The algorithm is based on the analytic inversion of a quasi-static model of the flow through a radial turbine with a bypass valve in parallel.

The estimation methodology was first illustrated for single stage turbine, and then extended to a more complex case of a Diesel engine with a two stage turbocharger including a variable geometry HP turbine with bypass valve and a fixed geometry LP turbine with waste-gate valve.

The estimator was identified on engine steady-state data obtained by a validated mean value model of a Diesel engine with two stage turbocharger. Validation of the estimator in both steady state and transient operation (FTP driving cycle) was performed against simulation data, showing show satisfactory accuracy in both steady state and transient conditions.

Future research activity will be oriented to extending the proposed estimation scheme, including a feedback loop, and providing experimental validation.

\section{ACKNOWLEDGMENTS}

The present work was sponsored by General Motors Research, Development and Strategic Planning. The authors are grateful to Yongsheng $\mathrm{He}$ for providing the data utilized in this study.

\section{REFERENCES}

[1] H. Yokomura, S. Kohketsu, S. Kotooka and Y. Akao. "Transient EGR Control for a Turbocharged Heavy Duty Diesel Engine". SAE Technical Paper 2004-01-0120.

[2] H. Itoyoma, M. Uchida and H. Miwa. "A Study of an EGR Control System for Diesel Engines Based on an Intake/Exhaust System Model". SAE Technical Paper 970621.

[3] B. Lu, Y. Minggao. "Coordinated Control of EGR and VNT in Turbocharged Diesel Engine Based on Intake Air Mass Observer". SAE Technical Paper 2002-01-1292.

[4] A. Amstutz, L. Guzzella. "Control of Diesel Engines", IEEE Control Systems Magazine, Vol 18, Issue 5, 1998.

[5] A. Stefanopoulou, I. Kolmanovsky, J. Freudenberg. "Control of Variable Geometry Turbocharged Diesel Engines for Reduced Emissions", IEEE Transactions on Control Systems Technology, Vol. 8, Issue 4, 2000.

[6] J. F. Wright, D. E. Boewe. "System for Estimating Engine Exhaust Pressure'. United States Patent US 6,732,522.

[7] P. M. Olin. "A Mean-Value Model for Estimating Exhaust Manifold Pressure in Production Engine Applications" SAE Technical Paper 2008-01-1004.

[8] Y.Y.Wang and A. Gangopadhyay "Exhaust Backpressure Estimation for an Internal Combustion Engine with a Variable Geometry Turbo Charger", SAE 2009-01-0732.

[9] N.Watson, and M.S.Janota. "Turbocharging the Internal Combustion Engine", John Wiley and Sons, 1982.

[10] P. Moraal and I. Kolmanowsky. Turbocharger Modeling for Automotive Control Applications. SAE Technical Paper 1999-01-0908.

[11] M. Canova, P. Fiorani, A. Gambarotta, and M. Tonetti. "A Real-Time Model of a Small Turbocharged Multijet Diesel Engine: Application and Validation". Proceedings of the 7th International Conference on Engines for Automobile, 2005.

[12] Capobianco M., Gambarotta A. "A Method for the Evaluation of the Efficiency of Exhaust Turbochargers for Automotive Internal Combustion Engines". 41 ${ }^{\text {st }}$ ATI National Congress, Naples, 1986.

[13] M. Canova, F. Chiara, G. Rizzoni and Y.Y. Wang. "Design and Validation of a Control-Oriented Model of a Diesel Engine with Two-Stage Turbocharger". SAE Paper 2009-240122 . 